\title{
Erosion Vulnerability Assessment in REINA, Quezon Province, Philippines with Raster-based Tool Built within GIS Environment
}

\author{
Henry A. Adornado*1), Masao Yoshida ${ }^{2)}$ and Henry A. Apolinares ${ }^{3)}$ \\ 1) United Graduate School of Agricultural Science, Tokyo University of Agriculture and Technology, 3-5-8 Saiwai Chuo, Fuchu \\ Shi, Tokyo 183-8509, Japan \\ 2) Ibaraki University, College of Agriculture, 3-21-1 Chuo, Ami-Inashiki, Ibaraki Ken, 300-0393, Japan \\ 3) Bureau of Soil and Water Management (BSWM), Elliptical Road, Diliman, Quezon City, 1101, Philippines
}

\begin{abstract}
This study had developed a raster-based tool in order to automate the soil erosion vulnerability assessment. The tool that designed based on the empirical USLE (Wischmeier and Smith, 1978) was built using various available GIS geoprocessing tools. The data used in this study were prepared using Erdas Imagine and ArcGIS softwares. The cluster Municipalities of Real, Infanta and General Nakar (REINA), Quezon, Philippines were selected as study area as it was previously hit by strong typhoon that led to severe landslide and deluge in 2004. Damages to lives and properties were remarkably the biggest in the history of these Municipalities. Using the raster-based tool, erosion vulnerability was assessed. The results were categorized into six (6) classes. It showed that None to slight covers $33.42 \%$ of the total area while Very severe ranked second with $23.83 \%$. Other categories were Moderate with (2.26\%), High (14.05\%), Very high (18.80\%) and Severe (7.63\%) respectively. Higher percentage of None to slight can be justified by the fact that the area is still having $47 \%$ dense vegetation. However, high percentage of Very severe was attributed to presence of hundreds of bare/eroded areas in the mountain created by landslide due to heavy rain during a disaster in 2004. The developed tool is believed to be useful in the current situation wherein the country is on the process of nationwide hazard mapping.
\end{abstract}

\section{Key words}

Raster-based, soil vulnerability, model builder, USLE, geoprocessing tool, geohazard

\section{Introduction}

In the past years, several parts of the Philippines were hit by natural calamities like strong typhoon coupled by landslides. The disaster happened in 2004 was just one of the gloomy experiences. Rainfall is the major agent of erosion in the Philippines albeit soil type, vegetation, topography and farming practices are also contributing factors. Soil erosion is a physical process that entails soil detachment, transport and deposition of particles from one place to another. Though occurred naturally, anthropogenic activities have made occurrence and effect devastating.

The productivity of slopelands in the Philippines was reportedly declining due to population pressure and soil erosion (Pava et al., 1993; Paningbatan, 1992; Calanog and Calderon, 1990;

* Corresponding Author

E-mail: 50006953006@st.tuat.ac.jp
Escaño and Tababa, 1998). An estimated of 17.8 million people are living in the uplands (Cruz et al., 1988). With more than half of the country's total land area having a slope steeper than $18 \%$ (Escaño and Tababa, 1998; Adornado and Yoshida, 2008) soil erosion is likely to happen and steps to assess and mitigate this should be done. Determining how vulnerable a certain area to erosion is and by providing latest information in fast and efficient way could serve as basis for effective planning and policy making to abate the danger of having great damage caused by landslide. The Philippine government thru its concerned agency had started a geohazard mapping in the entire country to identify areas prone to flooding and erosion (MGB-CALABARZON, 2005).

Many studies and techniques implemented around the world about potential soil loss calculation were done. Most of them were based on Universal Soil Loss Equation (Wischmeier and Smith, 1978) and its revised version (RUSLE) (Renard et al., 1997). Others had modified part of the equation to fit in every 
country's situation. In this study, we tried to fast-track the process using the capabilities of GIS. In the developing nation like Philippines, collecting ample information is very difficult due to lack of expert engaged in such works and sophisticated equipments to be used nationwide. Thus, the tool was designed to accommodate and use the currently available data in the country by adopting some modified equations.

\section{Materials and Methods}

Availability of information is probably one of the significant considerations in selecting the model to be used. Using sophisticated model doesn't make sense if the data are inadequate (Van der Knijff et al., 1999). In this research, USLE was utilized due to its relative simplicity and robustness (Desmet and Govers, 1996). The general soil loss equation is as follows:

\section{$A=R^{*} K^{*} L S^{*} C^{*} P$}

Where: A is annual soil loss (ton/ha), $\mathrm{R}$ is rainfall and run-off factor, $\mathrm{K}$ is soil erodibility factor, LS is slope length and steepness factors, $\mathrm{C}$ is cover and management, and $\mathrm{P}$ is support practice factor.

Though many studies were done integrating USLE equation into GIS, those were implemented using normal way of calculating each factor one by one. What is new in this research is that, we converted the empirical equations into raster-based tool in such a way that the processes of some factors preparation and finally soil loss calculation were automated.

\section{Description of the study area}

The selected study area is located in Luzon Island, Province of Quezon. It has a total land area of 127, 851 hectares and covered by the cluster Municipalities of REINA. It is geographically located between latitude $14^{\circ} 35^{\prime} 27^{\prime \prime}$ to $15^{\circ} 00^{\prime} 42^{\prime \prime}$ North and longitude $121^{\circ} 21^{\prime} 36^{\prime \prime}$ to $121^{\circ} 44^{\prime} 01^{\prime \prime}$ East (Fig.1).

Based on PAGASA Philippines, the study area particularly the coast side (eastern part) which occupies bigger part of the area is falls within climatic type IV and partly in the western side within the province of Rizal is falls within type III. Type IV is characterized by having rainfall more or less evenly distributed throughout the year (January-December) while Type III is characterized by not very pronounced and relatively dry period from November to April and wet during the rest of the year. The calculated mean annual rainfall in the study area from 1994-2003 was $4131.85 \mathrm{~mm}$. The main landform in the western side (Mountainous area) are dominated by Mountains volcanic with Volcanic rocks, Basalt, Andesite and Tuff as parent materials and Hills volcanic in the eastern side with Andesite as parent material, whereas the broad alluvial plains in the lowlands are Alluvium (BSWMLREP). The elevation is ranging from $0-1320$ meters above sea level.

\section{Materials used}

Spot and ASTER images, paper maps of various kind (topographic, soil, landuse) and 10-year climatic data were utilized in the research. These were prepared and processed using Erdas
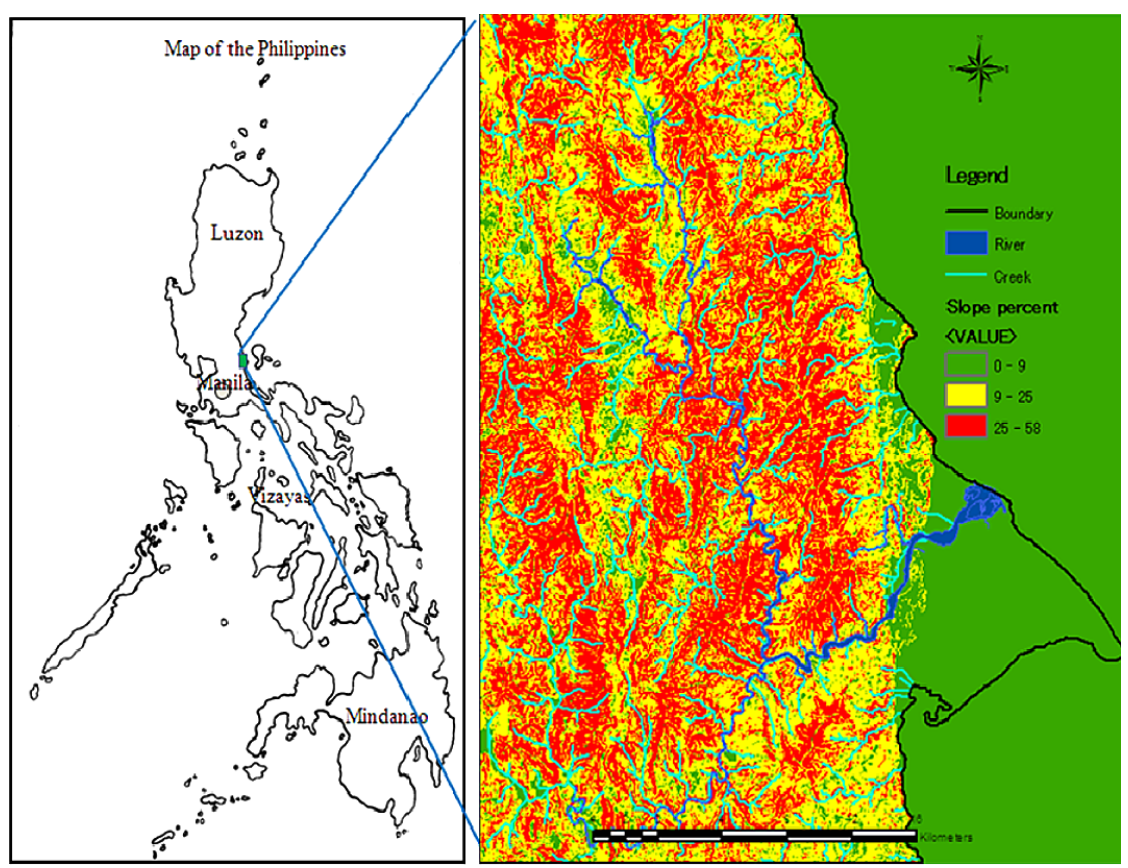

Fig. 1 Location of the study area 
Imagine 8.4 and ArcGIS 9.1.

\section{Datasets preparation}

The tool was designed following the data requirement defined in USLE and the availability of information to be used. Some approaches implemented by other researchers were adapted to make the tool fit in the country's situation. There were six factors used to calculate the annual soil loss and determine the erosion vulnerability as briefly described below.

$\mathbf{R}$ factor: Refers to the capacity of rainfall to erode certain type of soil. It is a measure of the total storm energy (E) and the maximum intensity $\left(\mathrm{I}_{30}\right)$ of the storm during a 30 minute period shortly expressed as $\mathrm{EI}_{30}$, (Wischmeier and Smith, 1978). The requirement for $\mathrm{R}$ factor calculation using this concept entails carefully collected series of storm measurements and needed much effort which is the prevailing problem in other countries where expert and measuring equipments are limited. However, there were other approaches implemented to calculate the R factor as reported by many authors. There was Modified Fournier's Index (Arnoldus, 1978) which altered the Fournier's Index formula (Fournier, 1960) by using the summation of monthly rainfall. It was found out as only applicable in certain regions. Eiumnoh, (2000) as reported by Thang et al., (2005) cited that the equation $\mathrm{R}=38.5+0.35 \mathrm{P}$ can be used to calculate $\mathrm{R}$ factor in the absence of detailed information. This simplified equation gave an acceptable result for tropical and sub-tropical ecological zones. Thus, we used in this study. P represents the mean annual rainfall. The calculated ten year mean annual rainfall (1994-2003) of the study area was converted into raster map and became an input to the USLE tool (Fig. 2). The tool had calculated the R factor using the formula first described by Eiumnoh.

K factor: Refers to the inherent soil erodibility which influenced greatly by soil texture and structure, organic matter, and permeability. It is a measure of susceptibility of soil particles to respond against detachment and transport caused by rainfall and surface run-off. This can be calculated using nomograph (Wischmeier and smith, 1978). Higher K factor value means the soil is highly susceptible to erosion.

The soil map available has insufficient information to determine $\mathrm{K}$ factor value though the amount of Organic Carbon (OC) was present. Thus the value of OC was converted into Organic Matter (OM) by multiplying to 1.72 (Walkley and Black, 1934). The results were then used to select the $\mathrm{K}$ factor value from the tabulated general magnitude of $\mathrm{K}$ factor value (Table 1), developed by Stewart et al., (1975) and reported by Mills et al., (1985); Mitchell and Bubenzer, (1980) and Novotny and Chester, (1981).

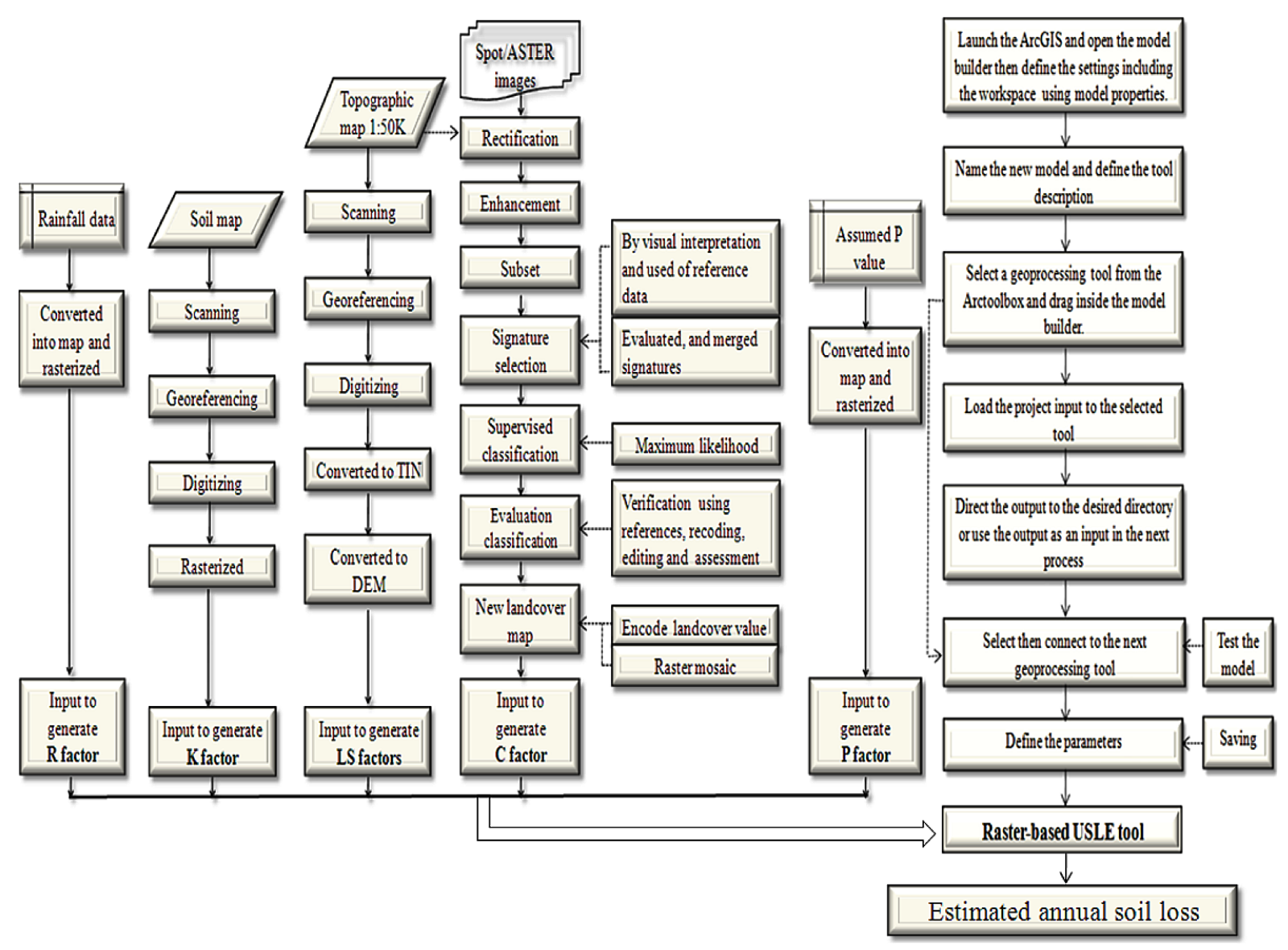

Fig. 2 Workflow of the study 
Table 1 Soil information and corresponding $K$ factor value.

\begin{tabular}{lcc}
\hline Soil texture & OM $(\%)$ & K factor value \\
\hline Clay & 4.47 & 0.20 \\
Clay loam & 4.47 & 0.21 \\
Loamy sand & 2.06 & 0.10 \\
Sandy loam & 0.17 & 0.27 \\
Silty clay & 3.44 & 0.19 \\
\hline
\end{tabular}

Source: Stewart et al., 1975.

Goldman et al., (1986) on the other hand noted that the simpler and more conservative approach is to use the highest $\mathrm{K}$ value obtained. The soil map obtained was scanned, georeferenced and digitized then the corresponding $\mathrm{K}$ values were encoded and rasterized to use as input to the USLE tool (Fig. 2). The K factor value is ranging from 0.1 to 0.27 .

LS factor: Refers to the ratio of the soil loss from actual field slope length of a standard field plot with 22.13 meters long, equivalent to $72.6 \mathrm{ft}$. and the ratio of the soil loss from the actual field slope gradient of a $9 \%$ standard plot. The steeper and longer the slope, the higher is the risk to erosion.

The LS calculation was reportedly problematic when applied to a catchment scale (Griffin et al., 1988; Moore and Wilson, 1992; Renard et al., 1991; Hickey, 2000). Since actually measuring the LS factor is impractical due to too much effort needed, several approaches were implemented. The developed approaches to calculate slope length includes grid based approach (Hickey et al., 1994), the unit stream power theory (Mitasova, 1993), while Cowen (1993) had used the cumulative downhill slope length. Many had suggested however the use of upslope contributing area (Moore and Wilson, 1992, Moore and Burch, 1986, Mitasova et al., 1996, Desmet and Govers, 1996). The impact of replacing the slope length by upslope area better reflects the increased erosion in areas of concentrated flow and permits to identify areas with potential gully erosion (Mitasova et al., 1996). In this paper, the equation that utilizes the upslope contributing area was considered. The raster-based tool had calculated the LS factors using the equation described below to use upslope contributing area.

$$
\mathrm{LS}=(\mathrm{m}+1)\left[\mathrm{A} / \mathrm{a}_{0}\right]^{\mathrm{m}}\left[\sin \mathrm{b} / \mathrm{b}_{0}\right]^{\mathrm{n}}
$$

Where: A is upslope contributing area per unit contour width; $\sin =$ sine value of the slope; $b$ (in deg.) is the slope, $m$ and $n$ are parameters, and $\mathrm{a}_{0}=22.1 \mathrm{~m}=72.6 \mathrm{ft}$ is the length and $\mathrm{b}_{0}=0.09$ $=9 \%=5.16 \mathrm{deg}$. is the slope of the standard USLE plot. The values of $\mathrm{m}(=0.6)$ and $\mathrm{n}(=1.3)$ were empirically derived.

In this research, DEM was generated to calculate LS factors. It was originated from a topographic map with 20 meters interval and 1:50,000 scale. It was scanned, georeferenced, digitized, and
Table 2 Landcover generated and corresponding $\mathbf{C}$ factor values

\begin{tabular}{llc}
\hline \multicolumn{1}{c}{ Landuse } & C factor & Area (\%) \\
\hline Water & 0.0001 & 1.45 \\
Concrete/boulders/asphalt & 0.0001 & 0.42 \\
Thin forest/coconut & 0.003 & 23.90 \\
Bare/eroded area & 1.0 & 2.48 \\
Dense vegetation & 0.002 & 47.26 \\
Agri. Area/rice field & 0.377 & 10.08 \\
Shrubs/grasses & 0.14 & 14.37 \\
\hline
\end{tabular}

Sources : Wischmeier and Smith, (1978) and Morgan, (1995).

converted into Triangulated Irregular Networks (TIN) and finally into Digital Elevation Model (DEM) (Fig. 2). This DEM became an input to the raster-based tool to calculate the LS factors using the above-cited modified equation.

C factor: Refers to the ratio of soil loss under a given crop or a land cover condition from bare soil. The higher the $\mathrm{C}$ value, the higher the erosion risk. In this research, a SPOT and ASTER satellite images were used to generate new land cover map. Each image was rectified to the correct projection of the study area using topographic map and enhanced the brightness for better visual interpretation. The image covers wide area, thus, subsetting was implemented to focus the processing in the study area. Other parts of the image were cloudy that may possibly affect the classification, subsetting was therefore very important.

Selection of sample signatures was done to discriminate the information in the image. A total of 26 signatures were selected. These signatures represents land cover classes present in the image. Supervised classification was then implemented using maximum likelihood algorithm. The thematic raster generated had undergone careful evaluation, verification, recoding and editing. Finally the classes were reduced to 7 categories. Then the land cover factor value as suggested by Wischmeier and Smith, (1978) and Morgan, (1995) were encoded for each class. The classified images were mosaicked (Fig. 2) to complete the area wide map. Result was new land cover map which served as an input to the tool. The $\mathrm{C}$ factor is ranging from 0.0001 to 1.0 (Table 2).

P factor: Refers to the ratio between the erosion occurred in the field with soil conservation practices. There was no support practice or soil conservation measures observed in the study area. Thus, a $\mathrm{P}$ factor value of 1 was utilized. A raster datum with a value of 1 was generated and became an input to the USLE tool.

\section{Building raster-based USLE tool}

Building the tool was implemented in the ArcGIS 9.1 by selecting and combining various readily available geoprocessing tools inside the Arc toolbox. Fig. 3 below shows the diagram of selected and interconnected geoprocessing tools inside the rasterbased tool. 


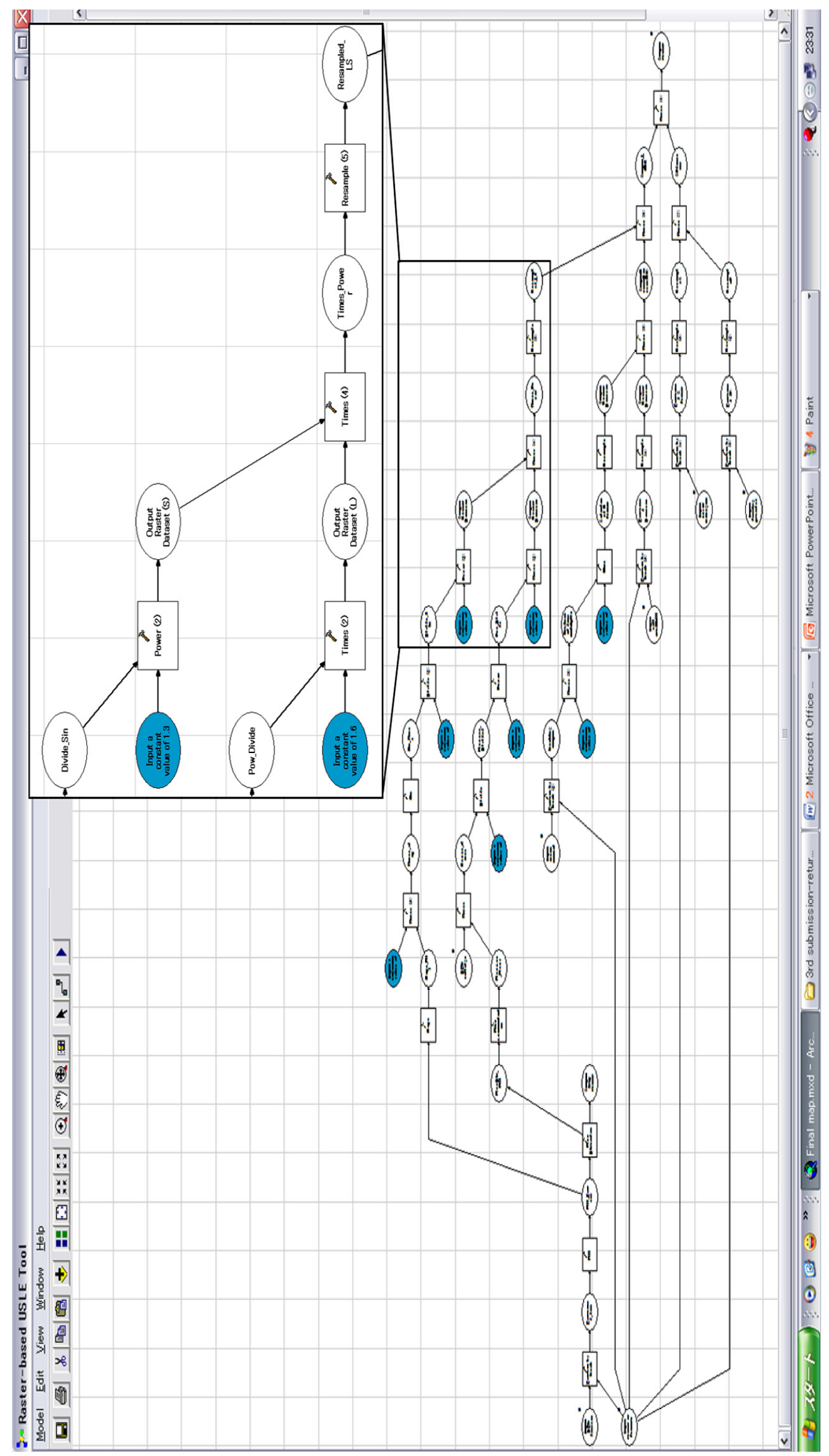

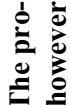

总

鱼 
Geoprocessing serves the purpose mainly to allow automation of GIS tasks. It allows chaining of tools together and feeding the output of one tool to another (ESRI geoprocessing manual). The tool was developed within the GIS model builder which is a design environment for creating workflow diagram and functioned more than just a processing tool (Ormsby et al., 2004).

Launching the ArcGIS and opening the model builder were first in the steps, followed by defining settings including the workspace (Fig. 2). It is always imperative to define the workspace because this will serve as depository area of all files to be generated during the process. Next steps were naming the model and defining its description in order to describe what this tool is all about and what it is capable of doing for the benefit of the users. Then choosing the necessary geoprocessing tool from the toolbox and added to the model builder. The data were then inputted and the output was directed to desired folder and directory. You can then select another tool and connect with the already chosen tool inside the model builder. The output data in the first process can be used as an input in the next process depending on what the model required. It is good practice to run each process inside the model builder every time a new tool was added and have the results checked. When the model diagram was done (Fig. 3), parameters were defined to determine the tool input and output.

\section{Results and Discussions}

\section{Raster-based USLE tool}

USLE tool is as easy to use as any other geoprocessing tool inside the ArcGIS environment. This can be docked anywhere in the monitor akin to any other tool inside GIS (Fig. 4).

The raster datasets prepared (R, K, LS, C and P factors) were inputted in the raster-based tool and the tool eventually had calculated the R and LS factors from rainfall and DEM datasets using the equation described in the above chapters. Finally the potential annual soil loss was computed by multiplying the factors with each other. All these procedures were done by the USLE tool. The model builder allows the user to design a model according to their choice. It also recognizes the script model to supplement the geoprocessing tools, though a programming knowledge is required. Noted that the presence of various modified equations and relevant data available, the tool can always be modified or redesigned based on one's preference. The equations used in this study were empirically tested though using them in large scale might not be hundred percent accurate as it was tested in relatively small area. Nonetheless, the intent of providing overview of the erosion extent was served. The calculation result of the developed tool was validated by using one by one calculation as

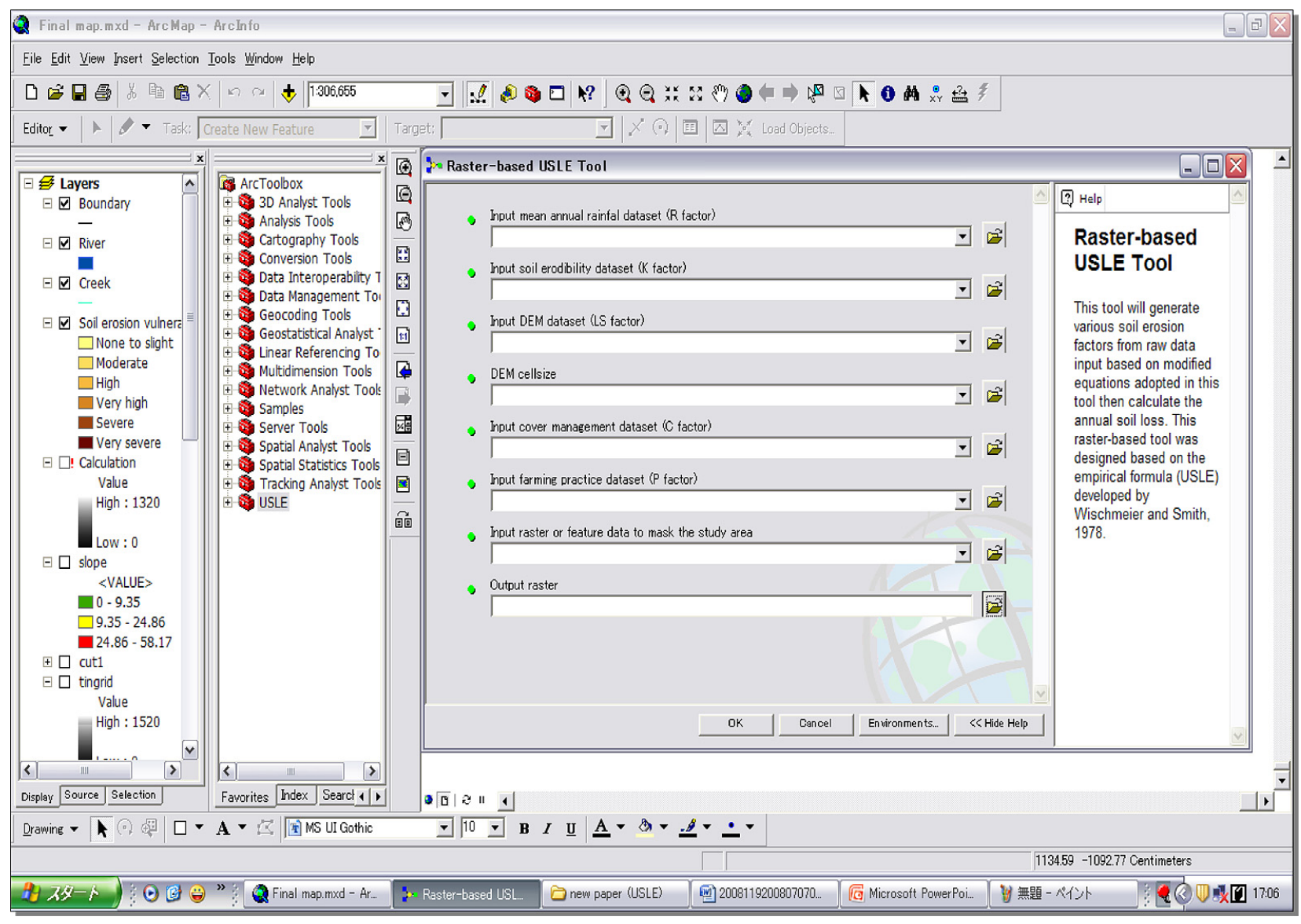

Fig. 4 Raster-based USLE tool 


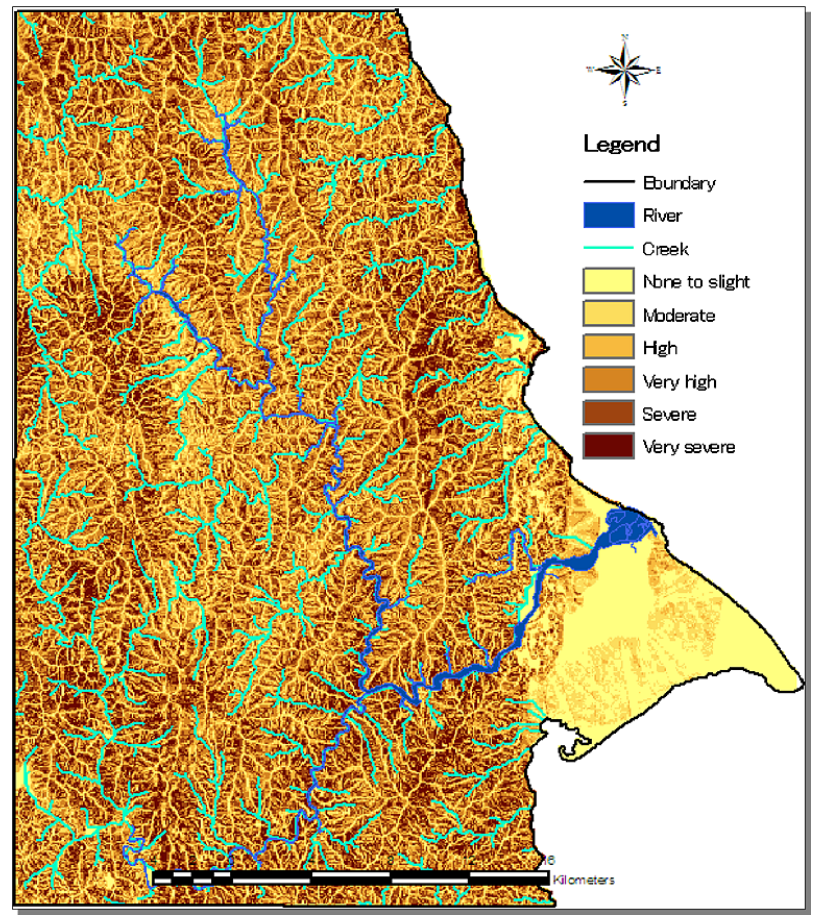

Fig. 5 Soil erosion vulnerability map

normally employed by others. They both produced similar results suggesting that the output from the automated procedure was accurate. The results of the study could be used as reference in planning, policy making and disaster preparedness strategy. For instance, upon knowing that certain area is within the very severe, it can alert the concerned authorities so that they can formulate strategies/plans what possible actions shall be taken just in case of emergency and determine who would be affected. Moreover, they can use the result as reference to identify the location that needed immediate erosion prevention measures. When there is a heavy rainfall, the residents in and/or near highly sloping and denuded areas could be advised to take necessary action for possible erosion.

\section{Extent of soil vulnerability}

The soil erosion vulnerability was classified according to the rate of potential soil losses given the prevailing climatic condition, soil characteristics, land cover type and topographic conditions.

As shown in the vulnerability map (Fig. 5), light yellow represents areas with None to slight while dark brown represents areas with very severe soil loss potential. It clearly depicted that those areas with steep slopes and less vegetation have greater soil loss estimate.

The results were categorized into six (6) classes. It showed that None to slight covers $33.42 \%$ of the total area while Very severe ranked second with $23.83 \%$. The former has an estimated of $0-5$ ton per hectare whereas the latter has more than 300 ton per hectare of potential soil loss annually. Other categories were
Table 3 Soil vulnerability classes

\begin{tabular}{lcrr}
\hline \multicolumn{1}{c}{ Classes } & Soil loss (t/ha/yr) & Area (ha) & \multicolumn{1}{c}{$\%$} \\
\hline None to slight & $0-5$ & 42715.49 & 33.42 \\
Moderate & $5-15$ & 2890.37 & 2.26 \\
High & $15-50$ & 17956.76 & 14.05 \\
Very high & $50-150$ & 24042.58 & 18.80 \\
Severe & $150-300$ & 9753.25 & 7.63 \\
Very severe & $>300$ & 30465.79 & 23.83 \\
\hline
\end{tabular}

Moderate with an estimated of 5-15 (2.26\%, High with 15-50 (14.05\%), Very high with 50-150 (18.80\%) and Severe with $150-300$ ton/ha (7.63\%), respectively (Table 3 ).

Higher percentage of None to slight was attributed to the presence of around $47 \%$ dense vegetation (Table 2). However, high percentage of Very severe was perhaps caused by the presence of hundreds of bare areas and eroded portion sporadically distributed in the mountain created by landslide during 2004 typhoon as observed in the satellite image. The high precipitation rate in the study area has probably influenced the high vulnerability to erosion.

\section{Conclusion}

The richness of geoprocessing tools within the GIS has offered multiple uses in different fields. It showed that even calculation that entails complex mathematical equation can be converted into simple tool that even ordinary people with simple computer knowledge can use to automate the process. Remote sensing techniques had also manifested its convenience in information extraction from digital data to fill in the lacking data needed.

The effectiveness of the tool and the use of modified equation in calculating LS factor could be seen as it vividly showed the high susceptibility to erosion especially those areas falls in steep slopes and with less vegetation (Fig. 5). This equation however, suggests that deposition areas be excluded as in this model assumed that transport capacity exceeds detachment everywhere (Mitasova et al., 1996).

The development of this kind of tool can enhance and fast-tract the assessment of soil vulnerability to erosion. This is believed to be useful especially at this point in time that our country, the Philippines is on the process of generating hazard mapping nationwide to include erosion risk map.

\section{References}

Adornado, H. A. and Yoshida, M. (2008): Crop suitability and soil fertility mapping using Geographic Information System (GIS). Agricultural Information Research, Vol. 17, No. 2, pp. 60-68.

Arnoldus, H. M. J. (1978): An approximation of the rainfall factor in the Universal Soil loss Equation. In: De Boodt, M. \& Gabriels, D. (eds): 
Assessment of erosion, pp. 127-132. Wiley, Chichester.

Bureau of Soil and Water Management (BSWM-LREP): Land Resources Evaluation Project; Physical Land Resources, Quezon Province: Vol. 1. DA-BSWM, Quezon City, Philippines.

Calanog, L. and Calderon. (1990): The Philippine upland communities: Socio-demographic update. In: Highlights '95. PCARRD, Los Baños, Laguna. p. 167

Cowen, J. (1993): A proposed method for calculating the LS factor for use with the USLE in a grid-based environment: Proceedings of the $3^{\text {th }}$ annual ESRI user conference, pp. 65-74.

Cruz, C. J., I. Zosa-Feranil, and C. L. Goce., (1988): Population pressure and migration: Implications for upland development in the Philippines. Journal of Philippine Development 26, 15.

Desmet, P. J. J., and G. Govers, (1996): A GIS procedure for automatically calculating the USLE LS factor on topographically complex landscape units. Journal of Soil and Water Conservation 51, pp. 427-433.

Eiumnoh, A. (2000): Integration of Geographic Information System (GIS) and Satellite Remote Sensing (SRS) for watershed management, Technical Bulletin 150. Food and Fertilizer Technology Center, Taiwan.

Escaño C. R. and S. P. Tababa (1998): Fruit Production and the Management of Slope lands in the Philippines: Food and Fertilizer Technology Center for the Asian and Pacific Region. http://www.agnet.org/ library/eb/450/.

ESRI geoprocessing manual.

Fournier, F. (1960): Climat et érosion. Presses Universitaires de France, Paris.

Goldman, S. J., Jackson, K. and Bursztynsky, T. A. (1986): Erosion \& Sediment Control Handbook, McGraw-Hill Book Company, New York, W87-08686.

Griffin, M. L., Beasley, D. B., Fletcher, J. J. and Foster, G. R. (1988): Estimating soil loss on topographically non-uniform field and farm units. Journal of Soil and Water Conservation, 43, 326-331.

Hickey, R. (2000): Slope Angle and Slope Length Solutions for GIS. Cartography, Vol. 29, no. 1, pp. 1-8.

Hickey, R., Smith, A. and Jankowski, P. (1994): Slope length calculations from a DEM within Arc/Info GRID. Computers, Environment, and Urban Systems, 18(5), 365-380.

Mills, W. B., D. B. Porcella, M. J. Ungs, S. A. Gherini, K. V. Summers, G. L. Lingfung Mok, G. L. Rupp, and G. L. Bowie (1985): Water Quality Assessment: A Screening Procedure for Toxic and Conventional Pollutants, EPA-600/6-82-004a \& b. Volumes I and II. U.S. Environmental Protection Agency, Washington DC.

Mines and Geosciences Bureau-CALABARZON, (2005): Flood hazard mapping of Real, Infanta and General Nakar, Quezon. DENRMGB, CALABARZON, Manila Philippines.

Mitasova, H. (1993): Surfaces and Modeling. Grassclippings, 7(1), 1819.

Mitasova, H., J. Hofierka, M. Zlocha, L.R. Iverson, (1996): Modeling topographic potential for erosion and deposition using GIS. Int. Journal of Geographical Information Science, 10(5), 629-641.

Mitasova H., L. Mitas, W. M. Brown, D. M. Johnston, (1999): Terrain Modeling and Soil Erosion Simulations for Fort Hood and Fort Polk Test Areas. http://skagit.meas.ncsu.edu/ helena/gmslab/reports/ cer199/rep99.html.

Mitchell, J. K. and G. D. Bubenzer, (1980): Soil loss estimation, Soil erosion. (M. J. Kirkby and R. P.C. Morgan, Eds.) John Wiley and Son. pp. 17-62.
Moore, I. and Burch, G. (1986) Physical basis of the length-slope factor in the Universal Soil Loss Equation. Soil Society of America Journal, 50, 1294-1298.

Moore, I. D. and Wilson, J. P. (1992) Length-slope factors for the revised universal soil loss equation: simplified method of estimation. Journal of Soil and Water Conservation, 47(5), 423-428.

Morgan, R. P. C. (1995): Soil Erosion and Conservation (Second Edition). Longman Group, UK Limited.National Mapping and Resource Information Administration (NAMRIA), DENR-NAMRIA, Makati, Philippines.

Novotny, V., and G. Chesters, 1981. Handbook of Non-point Pollution. Van Nostrand Reinhold, NY.

Ormsby, T., Napoleon, E., Burke, R., Groess, C., and Feaster, L. (2004): Getting to know ArcGIS Desktop, $2^{\text {nd }}$ Edition. Updated for ArcGIS 9: Chapter 20, Creating Models, pp. 517-541.

Paningbatan, E. P., A. R. Maglinao, L. A. Calanog and G. M. Huelgas. (1992): Management of sloping lands for sustainable agriculture in the Philippines. In: Technical Report on the Management of Sloping Lands for Sustainable Agriculture in Asia, Phase 1, 1988-1991 (IBSRAM/ASIALAND). Network Document No. 2. IBSRAM, Bangkok, Thailand. (Unpublished mimeograph).

Pava, H. M., J. B. Arances, J. M. Magallanes, I. O. Mugot, I. S. Sealza, J. M. Manubag and L. A. Chua. (1993): Mindanao upland stabilization and utilization through proper agro-forestry networking program (MUSUAN), Phase III. Terminal Report - (CMU-FORD Foundation Project). (Unpublished mimeograph).

Philippine Atmospheric, Geophysical and Astronomical Services Administration (PAGASA), DOST Philippines: http://www.pagasa.dost. gov.ph/.

Renard, K., Foster, G. R., Weesies, G. A. Porter, J. P. (1991): (RUSLE) Revised Universal Soil Loss Equation. Journal of Soil and Water Conservation, 46, 30-33.

Renard, G. R. Foster, G. A. Weesies, D. K. McCool and D. C. Yoder, (1997): Predicting soil erosion by water: A guide to conservation planning with the Revised Universal Soil Loss Equation (RUSLE). In: Agric. Handbook Vol. 703, USDA, Washington, D.C., pp. 1251.

Stewart, B. A., D. A. Woolhiser, W. H. Wischmeier J. H. Caro, and M. H. Frere, (1975): Control of Water Pollution from Cropland, Vol. 1. A manual for guideline development. USEPA and USDA, Report Nos. EPA-600/2-75 026a and ARS H-5-1, Washington, DC.

Thang, C. C., A. Euimnoh, G. P. Shivakoti and R. Clemente, (2005): Spatial Modeling for Land Degradation Assessment Using Remotely Sensed Data and Geographic Information System; A Case Study of Daungnay Watershed, Magway District, Myanmar http://www. gisdevelopment.net/application/environment/land/ma05222pf.htm.

Van der Knijff J. M. and Jones R. J. A. Montanarella L. (1999): Soil erosion risk in Italy: http://eusoils.jrc.it/ESDB_Archive/eusoils_docs/ other/er_it_new.pdf

Walkley A. and Black, I. A. (1934): An examination of the DEGTJAREFF method for determining soil organic matter and a proposed modification of the chromic acid titration method. Soil Sci., 37, pp. 29-38.

Wischmeier, W. H. and D. D. Smith, (1978): Predicting rainfall erosion losses, a guide to conservation planning. Agric. Handbook Vol. 537, USDA, Washington, D.C.

Received July 7, 2008

Accepted November 24, 2008

Environmental Information 